\title{
BREVES INDICAÇÕES SOBRE O CONTEXTO HISTÓRICO, OS LIMITES E AS CONTRADIÇÕES DA ESQUERDA HEGELIANA ${ }^{1}$
}

\author{
Frederico Jorge Ferreira Costa ${ }^{2}$
}

\begin{abstract}
Resumo:
O presente artigo é expressão de um dos momentos de pesquisa pós-doutoral centrada na construção do método em Karl Marx, o que exigiu um diálogo crítico com a filosofia neohegeliana, em particular com a denominada, não sem divergências, esquerda hegeliana. Nesse sentido, busca-se inserir o neohegelianismo no contexto das contradições de classes próprias da realidade alemã do século XIX. O núcleo central da análise é a relação entre filosofia da esquerda hegeliana e a possibilidade de constituição de um movimento liberal no quadro histórico de emergência política do proletariado. Por meio da leitura imanente de fontes primárias, de pesquisadores da temática e intérpretes, esta exposição estrutura-se em três partes. Primeiramente, a exposição da realidade alemã na transição dos séculos XVIII-XIX, sem a qual é impossível compreender a constituição da esquerda hegeliana. Em segundo lugar, apresentam-se os contornos gerais do pensamento de Hegel, em seus elementos progressivos e contraditórios. Por último, levantam-se indicações a partir de problematizações sobre contribuições selecionadas de pensadores emblemáticos da denominada esquerda hegeliana com suas contradições e limitações frente ao horizonte alemão da luta de classes.
\end{abstract}

Palavras-chave: Alemanha; Neohegelianismo; Luta de Classes.

\section{BRIEF INDICATIONS ABOUT THE HISTORICAL CONTEXT, THE LIMITS AND CONTRADICTIONS OF THE HEGELIAN LEFT}

\begin{abstract}
:
This article is an expression of one of the moments of postdoctoral research centered on the construction of the method in Marx, which necessitated a critical dialogue with the neohegelian philosophy, in particular with the so-called, not without disagreements, hegelian left. In this sense, it is sought to insert neohegelianism in the context of the contradictions of classes proper to the german reality of the nineteenth century. The central nucleus of the analysis is the relation between philosophy of the Hegelian left and the possibility of constitution of a liberal movement in the historical picture of political emergency of the proletariat. Through the immanent reading of primary sources, researchers of thematic and interpreters this exhibition is structured in three parts. First, the exposition of the german reality in the transition from the eighteenth to the nineteenth centuries, without which it is impossible to understand the constitution of the hegelian left. Second, the general contours of Hegel's thought are presented in their progressive and contradictory elements. Finally, indications are drawn from problematizations on selected contributions of emblematic thinkers of the so-called hegelian left, with their contradictions and limitations in the face of the german horizon of the class struggle.
\end{abstract}

Keywords: Germany; Neohegelianism; Class Struggle

1 Este texto é resultado de pesquisas realizadas no Estágio Pós-doutoral em Filosofia na Universidade Federal do Ceará - UFC, que versou sobre a constituição do método em Marx entre 1843 e 1857, sob a supervisão do professor Doutor Eduardo Ferreira Chagas.

2 Doutor em Educação. Professor da Faculdade de Educação de Itapipoca da Universidade Estadual do Ceará - FACEDI/UECE. Pesquisador colaborador do Instituto de Estudos e Pesquisas do Movimento Operário - IMO. Membro do Programa de Pós-graduação em Educação - PPGE/UECE e do Mestrado Acadêmico em Serviço Social, Trabalho e Questão Social - MASS/UECE. Coordenador do Grupo de Pesquisas Ontologia do Ser Social, História, Educação e Emancipação Humana GPOSSHE. Email: frederico.costa@uece.br. 


\section{BREVES INDICACÕES SOBRE O CONTEXTO HISTÓRICO, OS...} Frederico Jorge Ferreira Costa

\section{Introdução}

Este texto é produto de pesquisa realizada em estágio pós-doutoral sobre a construção do método em Karl Marx, o que conduziu ao estudo de alguns elementos da denominada filosofia neohegeliana, particular da esquerda hegeliana. Seu objetivo é traçar, de forma provisória, as coordenadas categoriais do movimento da esquerda hegeliana no contexto da realidade alemã, pois entende que, dessa maneira, é possível compreender as elaborações da esquerda hegeliana como uma resposta historicamente posta à determinada situação econômica, social, política e cultural.

Neste artigo há apenas um anúncio, uma notícia, sobre um tema em si tão vasto e importante para a compreensão da superação da herança hegeliana no pensamento marxiano e engelsiano no processo de constituição do materialismo histórico.

Sob a caracterização da corrente filosófica hegeliana pós Hegel há divergências. No entanto, em um primeiro momento, cabe certo grau de generalização, contanto que se leve em conta considerações como a seguinte:

\footnotetext{
Muitas vezes, a divisão da escola hegeliana estabelecida por Strauß baseando-se nas discussões em torno da filosofia da religião - entre hegelianos de esquerda e de direita foi identificada com outra divisão: aquela entre os "jovens" e os "velhos" hegelianos. Os velhos hegelianos são considerados conservadores (logo, de direita), os jovens são vistos como progressistas ou até revolucionários (logo, de esquerda). Atualmente, as designações "hegelianos de direita/velhos hegelianos", de um lado, e "hegelianos de esquerda/jovens hegelianos", de outro, são vistas praticamente como sinônimas. Da mesma forma tornou-se comum associar a Marx e Engels determinada fase "jovem-hegeliana" mais ou menos marcante. Todavia, a própria literatura especializada tem grande dificuldade em definir tanto o hegelianismo velho e de direita quanto o jovem e de esquerda; definição que normalmente só funciona com grandes generalizações. Além disso, quase não há consenso em relação ao pertencimento de certos representantes a uma ou a outra corrente. Portanto, não basta delinear o surgimento do "jovem hegelianismo"; é necessário discutir até que ponto tais divisões são de fato adequadas (HEINRICH, 2018, p. 315).
}

Nesse sentido, realiza-se neste estudo uma generalização não arbitrária ao inserir o neohegelianismo no contexto das contradições de classes próprias da realidade alemã do século XIX. O núcleo central desta análise centra-se na relação entre a filosofia neohegeliana e a possibilidade de constituição de um movimento liberal no quadro histórico de emergência política do proletariado. Daí a preferência pelo termo esquerda hegeliana.

\begin{tabular}{|c|c|c|}
\hline Q Rovista Dialectus & Ano 5 & n. 12 \\
\hline
\end{tabular}




\title{
BREVES INDICACÕES SOBRE O CONTEXTO HISTÓRICO, OS...
}

Frederico Jorge Ferreira Costa

Por meio da leitura imanente de fontes primárias, de pesquisadores da temática e intérpretes, esta exposição estrutura-se em três partes. Primeiramente, buscou-se expor a realidade alemã na transição dos séculos XVIII-XIX, sem a qual é impossível compreender a constituição da esquerda hegeliana. Em segundo lugar, são apresentados os contornos gerais do pensamento de Hegel em seus elementos progressivos e contraditórios. Por último, são levantadas indicações a partir de problematizações sobre contribuições selecionadas de pensadores emblemáticos da denominada esquerda hegeliana.

\section{Elementos do contexto histórico do surgimento da esquerda hegeliana}

O contexto da esquerda hegeliana deve ser compreendido no interior do ciclo histórico clássico das revoluções burguesas ${ }^{3}$. O período que interessa, de surgimento, contradições e limites da esquerda hegeliana está dominado pela Revolução Francesa que aboliu a monarquia absoluta, terminando de destruir a sociedade feudal para substituí-la pela sociabilidade burguesa o que acentuou em toda a Europa o antagonismo entre burguesia em ascensão e regime absolutista-feudal. Nesse cenário, a Alemanha estava atrasada em relação ao processo continental de revolução burguesa. $\mathrm{O}$ citado antagonismo era débil nas terras teutônicas em função do lento desenvolvimento econômico e social do país durante os séculos XVII e XVIII.

\begin{abstract}
Arruinada pelo descobrimento da América e da rota marítima das Índias, que afastava dela, em benefício das potências litorais do Atlântico, o comércio internacional; privada de seus elementos revolucionários pelo fracasso da guerra dos camponeses; dizimada pela Guerra dos Trinta Anos; desmembrada pelo Tratado de Westfália e impotente para recuperar-se desse desastre por causa de sua decadência econômica, a Alemanha havia permanecido dois séculos à margem da grande revolução industrial, que transformava então a Inglaterra e a França, e fazia passar progressivamente a produção do estágio artesanal ao manufatureiro, e depois ao fabril [...] ao final do século XVIII a Prússia era, do mesmo modo que o conjunto da Alemanha um Estado feudal com um regime de produção essencialmente agrário (tradução livre, CORNU, 1955, p. 3-4).
\end{abstract}

Nesse ambiente de atraso, os príncipes alemães combateram ativamente a Revolução Francesa e, depois, Napoleão Bonaparte, seu herdeiro. Porém, não

\footnotetext{
3 Considera-se o ciclo histórico clássico das revoluções burguesas o processo de conquista do poder político e de hegemonia da burguesia em diversos países, que se desenvolve entre o século XVII e o século XVIII: Revolta Holandesa ou Guerra dos 80 anos (1548-1649), Revoluções Inglesas de16401653 (Revolução Puritana) e de 1688-1689(Revolução Gloriosa), Independência dos Estados Unidos (1776) e Revolução Francesa (1789).
}

\begin{tabular}{|l|l|l|l|l|}
\hline Q Povista Qialectus & Ano 5 & n. 12 & Janeiro - Julho 2018 & p. 265-283 \\
\hline
\end{tabular}


conseguiram impedir as vitórias e as conquistas - econômicas, sociais, políticas, culturais e militares - da França burguesa da Convenção ${ }^{4}$, do Diretório ${ }^{5}$ e do Império Napoleônico $^{6}$ que tiveram, na Alemanha, profundas ressonâncias. Essas vitórias destruíram o antigo Império Alemão, convulsionaram o sistema feudal e semearam ideias revolucionárias em parte da Alemanha. Sob o impulso dessas ideias, formaramse, em especial nos meios intelectuais, uma corrente liberal que expressava os interesses de uma burguesia em vias de formação e que reclamava, junto com a liberdade, a igualdade política. Devido a opressão napoleônica, essa corrente liberal apresentou-se com um caráter nacional, pois aspirava à libertação e à unidade da Alemanha. Esse foi o motor do levante de 1813 que contribuiu poderosamente para a libertação da Alemanha e a queda de Napoleão em 1814.

Desde então, a Alemanha passou a ter a seguinte estrutura econômica, social e política:

a) Nos Estados puramente agrários do nordeste da Alemanha, nos quais a influência francesa foi muito débil, predominava quase absolutamente o despotismo e o sistema feudal;

b) na Prússia, as reformas de Stein e Hardenberg ${ }^{7}$ favoreciam o desenvolvimento capitalista na indústria e na agricultura, e robusteciam o poder da burguesia;

c) nos Estados do centro e do Sul, nas regiões de Baden, Wuttenberg, Hesse, Hanover, Baviera e Saxônia, onde a influência francesa penetrou mais profundamente, predominava um liberalismo moderado, sem uma base social muito profunda, posto que essas zonas eram em essência agrárias;

d) na Renânia ${ }^{8}$, e também em Westfália, o liberalismo tinha uma base mais sólida em razão da prolongada ocupação francesa e do rápido

4 Regime político que vigorou na França de 20 de setembro de1792 a 26 de outubro de 1795.

5 O Diretório foi o regime político adotado pela Primeira República Francesa entre 26 de outubro de 1795 (no calendário revolucionário, 4 de brumário do ano IV) e o golpe de Estado do 18 de brumário do ano VIII (9 de novembro de 1799). Foi assim chamado porque o poder executivo era exercido por cinco membros, denominados Diretores.

6 Durante o processo da Revolução Francesa, em 1799, com um golpe militar, Napoleão Bonaparte tomou o poder na França. Logo em seguida foi instituído o Consulado, constituído por três cônsules, e ele se tornou Primeiro Cônsul. Em 1802, foi proclamado Cônsul Vitalício e, dois anos depois, Napoleão, autorizado por meio de plebiscito, autoproclamou-se Imperador. Arruinado, após a campanha militar da Rússia, renuncia em 1814 e é exilado na Ilha de Elba. Em março de 1815 retorna ao poder e é derrotado da Batalha de Waterloo, na Bélgica, em junho do mesmo ano. Finda-se o Primeiro Império Francês.

7 Depois das derrotas de Iena-Auerstedt (1806) para o exército napoleônico, a posterior entrada de Napoleão em Berlim e a Paz de Tilsit (1807), o Estado prussiano, sob a pressão dos acontecimentos e pela iniciativa dos ministros Stein e Hardenberg, iniciou um conjunto de reformas que beneficiou a burguesia: proclamou a liberdade de comércio e de indústria, concedeu maior a autonomia às cidades e suprimiu a servidão, porém deixando o campo sob o domínio da nobreza. Essas reformas que favoreceram a burguesia e a nobreza, dando pouca coisa ao campesinato, nada proporcionou ao proletariado que se formava nas cidades. Porém, mal Napoleão caiu, o rei da Prússia, Frederico Guilherme III, esforçou-se para restringir ao máximo a conquistas dessas reformas.

\begin{tabular}{|c|c|c|c|c|}
\hline Qevista Dialectus & Ano 5 & n. 12 & Janeiro - Julho 2018 & p. $265-283$ \\
\hline
\end{tabular}




\section{BREVES INDICACÕES SOBRE O CONTEXTO HISTÓRICO, OS...}

Frederico Jorge Ferreira Costa

desenvolvimento da indústria e da burguesia (tradução livre, CORNU, 1955, p. 4).

É nesse quadro complexo - no qual o Congresso de Viena, em 1814, fez da Alemanha uma Confederação de trinta e nove Estados soberanos -, que se apresentou o desenvolvimento desigual e combinado do capitalismo, até meados do século XIX. Tal processo, transformou o estado de espírito da própria burguesia alemã, que, com o tempo, adquiriu consciência de sua força com o aumento do seu poder econômico, tornando-se mais insistente em suas reivindicações. Essa postura influenciou o conjunto do modo de vida de diversas classes da sociedade alemã. A classe dominante continuou sendo a nobreza; a grande burguesia, apesar da crescente influência econômica, ainda era uma classe em formação; as classes médias situavam-se em uma medíocre existência; a situação dos camponeses complicava-se com a manutenção dos tributos pagos à nobreza e a oscilação nos preços dos produtos agrícolas; o proletariado, que ia se formando no ritmo do crescimento industrial, não estava protegido por nenhuma organização sindical nem legislação social, vítima da exploração burguesa e da concorrência da indústria estrangeira.

Nas primeiras décadas do século XIX, instaurou-se, em toda Alemanha, um conflito entre a burguesia, de tendência liberal que dirigia novas forças de produção, e os Estados reacionários, preocupados, antes de tudo, com a defesa dos interesses da nobreza agrária. Esse conflito reverberou na esfera ideológica numa luta entre um conjunto de concepções liberais inspiradas pela Revolução Francesa e concepções reacionárias que procuravam justificar tanto o feudalismo como o absolutismo. $\mathrm{O}$ movimento burguês não era monolítico, pela tensão interna entre burguesia liberal, camadas médias democráticas e setores populares com tendências radicais.

O movimento liberal e democrático, vencido no terreno político depois do Festival de Hambach $(1832)^{9}$, foi favorecido pelo desenvolvimento acelerado com a criação, em 1834, da União Aduaneira, que abarcou sucessivamente todos os Estados

8 A Renânia foi anexada à França entre 1795 e 1814, beneficiando-se com as reformas econômicas, administrativas, políticas e sociais da Revolução Francesa e do Império Napoleônico. Em 1815 foi anexada à Prússia, juntamente com a Westfália, o que gerou contradições por representar uma regressão econômica, social e política.

9 Por influência da Revolução de 1830, na França houve intensa pressão de tendência liberal em alguns Estados alemães, forçando seus soberanos a concederem uma Constituição a seus súditos. O apogeu desse movimento liberal se deu no Festival de Hambach no Palatinado, quando, no dia 17 de maio de 1832, aproximadamente 25.000 manifestantes reclamaram a unidade e um regime constitucional para toda a Alemanha. Porém, a burguesia não era bastante forte para que esse liberalismo pudesse triunfar. Os governos reprimiram com dureza as manifestações liberais, perseguindo os "demagogos" e restringindo a liberdade de imprensa.

\begin{tabular}{|c|c|c|c|c|}
\hline Rovista Dialectus & Ano 5 & n. 12 & Janeiro - Julho 2018 & p. $265-283$ \\
\hline
\end{tabular}




\section{BREVES INDICACÕES SOBRE O CONTEXTO HISTÓRICO, OS...}

Frederico Jorge Ferreira Costa

limítrofes da Prússia e constituiu um poderoso organismo econômico. Demonstrou grande vitalidade no terreno literário com o movimento "Jovem Alemanha" que opôs ao romantismo reacionário e ao conservadorismo do Estado prussiano e da Igreja os princípios da Revolução Francesa. Tal empreendimento, no entanto, foi reduzido ao silêncio pela interdição, pela reação, da publicação de seus livros em 1835.

Essa iniciativa estética de setores liberal-burgueses, porém, foi superada por um movimento político liberal não mais na esfera literária, mas no âmbito da filosofia, o movimento da esquerda hegeliana que se esforçaria para adaptar a filosofia hegeliana ao liberalismo.

\section{Hegel e a crise do hegelianismo}

Georg Wilhelm Friedrich Hegel (1770-1831) foi, no mundo pósRenascimento, o primeiro filósofo que buscou com rigor, sistematicidade e radicalidade, apreender a realidade enquanto historicidade. A filosofia hegeliana expressou a primeira concepção totalizante da história, procurando sintetizar a dinamicidade do ser em sua integridade. Isso porque

É precisamente em Hegel [...] que podemos indicar, em toda sua riqueza de determinações, as categorias essenciais daquilo que chamamos de tradição progressista, categorias que constituem o legado imperecível dessa grande época da humanidade para o conhecimento do real. O mérito essencial de Hegel reside nessa sua capacidade de sintetizar e elevar a um nível superior todos os momentos progressistas do pensamento burguês revolucionário. Podemos resumi-los, esquematicamente, em três núcleos: o humanismo, a teoria de que o homem é um produto de sua própria atividade, de sua atividade coletiva; o historicismo concreto, ou seja, a afirmação do caráter ontologicamente histórico da realidade, com a consequente defesa do progresso e do melhoramento da espécie humana; e, finalmente, a Razão dialética, em seu duplo aspecto, isto é, o de uma racionalidade objetiva imanente ao desenvolvimento da realidade (que se apresenta sob a forma de unidade dos contrários), e aquele das categorias capacidades de apreender subjetivamente essa racionalidade objetiva, categorias que englobam, superando, as provenientes do "saber imediato" (intuição) e do “entendimento" (intelecto analítico) (COUTINHO, 2010, p. 27-28).

Essas concepções de Hegel não surgiram como um raio em céu azul, responderam a injunções de ordem material e a uma tradição intelectual postas por sua época.

$\mathrm{Na}$ Alemanha, num primeiro momento diante das necessidades de uma burguesia nascente ainda muito débil que conciliava sua visão de mundo com o regime

\begin{tabular}{|c|c|c|}
\hline Q Rovista Dialectus & Ano 5 & n. 12 \\
\hline
\end{tabular}




\section{BREVES INDICACÕES SOBRE O CONTEXTO HISTÓRICO, OS...}

Frederico Jorge Ferreira Costa

absolutista e feudal, houve o surgimento do racionalismo alemão que limitava o progresso, como o fez o racionalismo francês do século XVII, a um desenvolvimento essencialmente espiritual e moral. Porém, ao fim do XVIII, ocorreu uma ampliação mais acelerada das forças produtivas, implicando numa conexão mais profunda dos seres humanos em relação à realidade natural e social. Frente a tudo isso, apresentou-se, na esfera da reflexão filosófica, a necessidade de superação do dualismo - problema não resolvido pelo racionalismo - que opunha o espírito à matéria, o homem à natureza,$- \mathrm{o}$ que resultou, como resposta, na elaboração de uma concepção totalizante do mundo concebido em seu movimento, da qual são partícipes, em suas particularidades teóricas, Hegel, Johann Gottlieb Fichte (1762-1814) e Friedrich Wilhelm Joseph von Schelling (1775-1854). Nesse sentido,

\footnotetext{
Talvez o modo mais econômico de esboçar essa atmosfera ou seus aspectos que mais nos ajudarão a entender Hegel seja delinear um problema central que insistentemente demandou uma solução dos pensadores dessa época. Ele dizia respeito à natureza da subjetivamente humana e sua relação com o mundo. Era o problema de unir duas imagens aparentemente indispensáveis do ser humano que, em certo nível, possuíam profundas afinidades uma com a outra, e, no entanto, não podiam senão se apresentar como completamente incompatíveis (TAYLOR, 2014, p. 23).
}

Essa inflexão da filosofia idealista alemã buscava uma solução à questão posta acima, nos limites de uma Alemanha que sofria as dores do parto de um capitalismo constrangido por forças do atraso.

Devido ao contexto histórico, tais pensadores foram incapazes de superar a contradição inerente ao regime capitalista, entre um processo de produção que socializa cada vez mais os homens e um modo de apropriação que isola os indivíduos, opondo-os uns aos outros. O idealismo alemão chegou a uma concepção totalizante sob uma forma ilusória, isto é, mediante uma espiritualização do homem e da natureza.

No esforço de superar o dualismo, os filósofos idealistas alemães Fichte, Schelling e Hegel viam o mundo como uma totalidade em incessante processo de transformação por obra de leis e forças internas. No entanto, reduziam o desenvolvimento da realidade ao desenvolvimento do espírito e o convertiam em princípio criador e regulador. Como em seus sistemas toda a realidade, no que tem de essencial, é dependente e se encontra incluída no espírito, este se converte em sujeito e objeto do processo real. A história do mundo se explicaria, então, pela autodeterminação do espírito.

\begin{tabular}{|c|c|c|}
\hline Q Rovista Dialectus & Ano 5 & n. 12 \\
\hline
\end{tabular}




\section{BREVES INDICACÕES SOBRE O CONTEXTO HISTÓRICO, OS...}

Frederico Jorge Ferreira Costa

Como concepção de mundo, considerado em seu devir, os citados filósofos expressavam as características do regime econômico novo - o capitalismo -, por isso colocavam em primeiro plano noções de transformação, desenvolvimento e progresso. Assim, ao estabelecer como objetivo do desenvolvimento do mundo a realização da liberdade, traduziram, na dimensão filosófica, tendências da burguesia a qual proclamava esse princípio como seu, tanto no terreno econômico como no social e político.

O sistema hegeliano emergiu de um conjunto de coordenadas filosóficas que, segundo Cornu (1955), poderiam ser centradas em quatro noções essenciais: a) a noção de que o espírito está indissoluvelmente ligado ao mundo que ele cria, exteriorizando sua essência nele, o que implicava a necessidade de não considerar as ideias, os fatos, os seres e as coisas não metafisicamente, em si mesmos, senão dialeticamente, em suas relações recíprocas e em seu devir; b) essa concepção dialética do mundo determinava a substituição da transcendência, que põe fora do mundo um princípio que o cria, pela ideia de imanência, que reintegra, por meio da história, o absoluto no mundo; c) também, posto que a realidade essencial era a realidade vivente, a fim de compreendê-la, seria preciso considerá-la em seu desenvolvimento, e, como consequência, o mundo deveria ser apreendido em sua transformação, em seu devir; por fim, d) emergia a tese que o elemento essencial do real não era a identidade que, ao suspender todo o movimento do mundo, fixa o real na imutabilidade; e sim a contradição que expressaria a permanente transformação das ideias, dos seres e das coisas, sendo a fonte de toda vida, o princípio de todo o devir e de todo o progresso.

Hegel levou essas características à radicalidade e a um elevado grau de elaboração, influenciando o movimento democrático pela mediação dos "jovens hegelianos". E mais, influiu profundamente na formação intelectual de Karl Marx (1818-1883) e Friedrich Engels (1820-1895), porque seu idealismo absoluto apresentava uma concepção totalizante mais concreta da realidade, unindo intimamente o espírito ao mundo e o homem à natureza de uma forma mais nítida. Isso trouxe implicações políticas e sociais para o momento histórico: as aspirações de uma burguesia alemã em vias de formação, desejosa de libertar-se das amarras de um sistema feudal ainda dominante, porém incapaz de derrotá-lo, por isso obrigada a conciliar com o referido regime e a monarquia absoluta.

\begin{tabular}{|c|c|c|}
\hline Q Rovista Dialectus & Ano 5 & n. 12 \\
\hline
\end{tabular}




\section{BREVES INDICACÕES SOBRE O CONTEXTO HISTÓRICO, OS...}

Frederico Jorge Ferreira Costa

Partidário, na juventude, de ideias revolucionárias burguesas, Hegel evoluiu, com o tempo, até um conservadorismo que chegou a ser reacionário. Tornou-se apologista da monarquia prussiana. Tal trajetória de vida indica o caráter contraditório de sua doutrina que apresenta uma tensão entre elementos progressistas e conservadores.

Ao mesmo tempo em que apreende o ser como processualidade, Hegel confina esse movimento na elaboração de um sistema concluso, o qual, na esfera política, termina pelo enaltecimento do Estado e, no plano teórico, por uma tão completa realização do ser que o suprime como movimento, o que se expressa bem na tese de "fim da história". Isso porque, em última instância

[...] Hegel se identificava com o ponto de vista do capital, com todas as suas inevitáveis limitações. Com isso, ele não poderia conceituar como algo irreprimivelmente aberto. Os determinantes ideológicos de sua posição estipulavam a necessidade de conciliação com o presente e daí o arbitrário encerramento da dinâmica histórica no quadro da 'sociedade civil' capitalista e de sua formação do Estado. A história poderia ser tratada como aberta, desdobrando-se até o presente, mas cujas portas voltadas para a direção de um futuro radicalmente diferente teriam que continuar fechadas" (MÉSZÁROS, 2002, p. 61).

Mesmo com essa contradição imanente, a filosofia de Hegel foi dominante na primeira metade do século XIX na Alemanha. Se a Alemanha não realizou a revolução no plano político-econômico e, muito menos, socialmente; por meio das reflexões filosóficas de Hegel, a nação alemã tornou-se contemporânea da revolução burguesa $^{10}$. Foi em torno do seu legado que gravitaram debates filosóficos-políticos até, aproximadamente, duas décadas após sua morte, que ocorreu em 1831.

\section{Pontuações críticas sobre a esquerda hegeliana: contradições e limites}

Em meados da década de trinta, começou a crise e dissolução da escola hegeliana. Essa crise se manifestou inicialmente por uma dupla leitura de Hegel. Engels (1985), mais tarde, realizando um balanço do pensamento hegeliano, o caracterizará como uma contradição entre o método e o sistema ${ }^{11}$. Nessa perspectiva, o método

10 “[...] nos anos mais importantes de sua formação intelectual, Hegel foi também um contemporâneo da Revolução Francesa de 1789 e de todos os levantes sem precedentes históricos que a seguiram dotados pela primeira vez na história, de um sentido significativamente global" (MÉSZÁROS, 2002, p. 55).

11 "Nomeadamente, colocando-se o fim da história no [facto] de a humanidade chegar ao conhecimento, precisamente, daquela Idéia (sic!) absoluta e de se declarar que esse conhecimento da Idéia (sic!) absoluta é alcançado na filosofia de Hegel. Com isto, declara-se, porém, todo o conteúdo dogmático

\begin{tabular}{|l|l|l|l|l|}
\hline Qevista 2 Dialectus & Ano 5 & n. 12 & Janeiro - Julho 2018 & p. 265-283 \\
\hline
\end{tabular}




\section{BREVES INDICACÕES SOBRE O CONTEXTO HISTÓRICO, OS...}

Frederico Jorge Ferreira Costa

hegeliano seria revolucionário por revelar a transitoriedade de todas as formas do ser.

Porém, o sistema, por ser conservador, acabava aprisionando essa transitoriedade do real em uma "camisa-de-força" finalística. De fato,

[...] o intento de Hegel de uma síntese universal deu logo lugar a resultados discordantes. Imediatamente depois de sua morte, ocorrida em 1831, se pôs em manifesto que sua teoria geral da consciência como sua aplicação ao significado da história e aos problemas do direito e da política eram suscetíveis de interpretações diferentes e contraditória. Em particular, não estava claro em que medida o conservadorismo político de Hegel era uma consequência natural de sua filosofia, ou bem se podia separar-se desta como uma opinião privada e pessoal (tradução livre, KOLAKOWSKI, 1980, p. 88).

No ambiente da Revolução de 1830, que assinalou o fim da Restauração na França e do sistema da Santa Aliança, o pensamento hegeliano não poderia sobreviver intacto aos efeitos do despertar econômico, social e político da Alemanha. Assim, com o tensionamento das contradições histórico-sociais, o antagonismo imanente ao pensamento hegeliano fez surgir duas vertentes básicas. De um lado, situou-se a denominada direita hegeliana ou velhos hegelianos, editores das obras de Hegel, que conservavam sua filosofia literalmente, mesmo quando faziam suas pesquisas singulares, como indica Löwith (2014). De maneira geral, esse setor fez uma leitura conservadora, por exemplo, da enigmática frase: "o racional é real; o real é racional”. De acordo com essa leitura, aquilo que existe o é conforme a razão, ou seja, é sancionado por ela. Evidentemente, tal postura teórica é legitimadora do que está posto. Se tudo o que existe é racional, o que atenta ou questiona o existente vai contra a razão. Essa postura não era sem fundamento na obra do mestre:

Por um lado, o hegelianismo era inexoravelmente anti-utópico: condenou expressamente o ponto de vista que, frente a uma determinada realidade histórica, coloca exigências baseadas em ideais normativos arbitrários, presunções moralistas e ideias de como deve ser o mundo. A dialética de Hegel era um método de compreensão da história passada, que não pretendia projetar-se em direção ao futuro; de fato, condenava qualquer extrapolação semelhante e não aspirava a configurar o curso dos assuntos humanos. Desse ponto de vista, poderia parecer que o hegelianismo significava que o reconhecimento da história e do status quo como realidades não menos inabaláveis que as regras da lógica, de forma que qualquer protesto contra o mundo presente em nome de outro imaginário deve ser rechaçar como o capricho, certamente compreensível porém estéril de uma consciência imatura (tradução livre, KOLAKOWSKI, 1980, p. 89).

do sistema de Hegel como verdade absoluta, em contradição com o seu método dialético dissolvente de todo o dogmático [alles Dogmatische]; com isto, o lado revolucionário fica abafado sob o [lado] conservador que [o] asfixia. E o que vale para o conhecimento filosófico, vale também para a prática histórica" (ENGELS, 1985, p. 382).

\begin{tabular}{|l|l|l|l|l|}
\hline Q Povista Dialectus & Ano 5 & n. 12 & Janeiro - Julho 2018 & p. 265-283 \\
\hline
\end{tabular}




\section{BREVES INDICACÕES SOBRE O CONTEXTO HISTÓRICO, OS... \\ Frederico Jorge Ferreira Costa}

Simultaneamente, a obra hegeliana, também,

Por outro lado, a apologia hegeliana da Razão podia tomar-se igualmente como o postulado de um mundo razoável, como a exigência de que a realidade se volte racional e a história empírica coincida com os requisitos do espírito em sua luta pela liberdade (tradução livre, KOLAKOWSKI, 1980, p. 89).

Nesse contexto, partindo de Hegel e expressando as contradições da realidade alemã, constituiu-se um grupo de jovens contestadores que apresentavam um Hegel exotérico, que fez cada vez mais concessões à reação e um Hegel esotérico mais oculto, cujo pensamento era necessário captar e era entendido com revolucionário. Logo,

[...] preferiram enfatizar o racional para contrapô-lo às mazelas da realidade, para mostrar que o momento da racionalidade ainda não tinha chegado e que ele só se efetivaria mediante a negação do existente e toda a sua gritante irracionalidade. O movimento da razão em direção à realidade, portanto, exige a superação do presente: este não é de forma alguma, o ponto final da história, mas um momento a ser necessariamente negado pelo movimento da Idéia (sic!) em sua marcha inexorável rumo à plena racionalidade (FREDERICO, 1995, p. 23-24).

Esse setor neohegeliano aplicou o método, exatamente sobre o que era o sinal mais explícito da ausência de revolução burguesa na Alemanha, ou seja, o caráter não laico do Estado. A evidência do atraso alemão era dada, precisamente, pela vinculação do poder estatal à Igreja, tanto católica como protestante. Em torno dessa temática religioso-política, iniciou-se a cristalização de posições no processo de crise do hegelianismo:

É significativo para a separação da escola hegeliana, em uma direita de velhos hegelianos e uma esquerda de jovens hegelianos, que ela não tenha nascido de diferenças filosóficas puras, porém de diferenças políticas e religiosas [...] Primeiro a distinção foi feita por Strauß e logo desenvolvida por Michelet, para deste então manter-se. A direita [...] seguindo a distinção hegeliana da religião cristã entre conteúdo e forma, acolheu positivamente o conceito de conteúdo, enquanto a esquerda submeteu, simultaneamente, à forma da representação religiosa o conteúdo da crítica. A direita queria conservar a história evangélica completa, a partir da ideia da unidade da natureza divina e humana, o centro [...] somente uma parte, e a esquerda afirmava que a partir da ideia não se poderiam manter os relatos históricos dos Evangelhos, seja total ou parcialmente (Löwith, 2014, p. 61-62).

Em suma, a esquerda hegeliana se manifestou aplicando o método à análise da religião. Em 1835, David Strauß (1808-1874) publicou A Vida de Jesus: criticamente

\begin{tabular}{|c|c|c|}
\hline Q Rovista Dialectus & Ano 5 & n. 12 \\
\hline
\end{tabular}




\section{BREVES INDICACÕES SOBRE O CONTEXTO HISTÓRICO, OS...}

Frederico Jorge Ferreira Costa

examinada, que determinou, pelas polêmicas suscitadas em torno da obra, a formação da "esquerda hegeliana". Segundo Strauss, três críticas deveriam ser feitas ao pensamento hegeliano (STRAUSS, 1902; CORNU, 1955): 1) sobre a religião mesma, seria possível reduzir a conceitos o conteúdo da fé sem deformá-la e, em tal caso, é possível enquadrar a verdade histórica e particular que representa uma religião nos marcos da verdade racional?; 2) em relação a Cristo: como podia conciliar-se a ideia geral de mediação entre Deus e o mundo, que representa para Hegel a pessoa de Cristo, com a existência particular e individual do Cristo dos Evangelhos?; finalmente, 3) se, como pensava Hegel, Deus se realiza progressivamente no curso da história humana, Cristo não pode representar nada mais que um momento dessa realização, e não é possível, portanto, atribuir à religião cristã um valor eterno e absoluto. Além disso, Strauss via nos Evangelhos não símbolos religiosos, mas mitos que traduziam as aspirações profundas do povo judeu, o que o levou a levantar o problema da historicidade da pessoa de Jesus. Inicialmente, pensou que a imagem de Cristo era incompleta e deformada e se propôs a extrair dos Evangelhos a figura verdadeira de Jesus. Falhou. Diante disso, rompeu com a concepção de um Jesus histórico. Então, retomou a ideia de um Deus impessoal que se confunde com a humanidade, o que está implícito na cristologia hegeliana.

Em função da polêmica gerada pelas reflexões de David Strauß, formou-se um grupo de hegelianos liberais, os jovens hegelianos, que formariam a esquerda hegeliana. Alinharam-se em oposição aos cristãos ortodoxos, que pretendiam subordinar a filosofia à religião, e contra os hegelianos conservadores, que buscavam assimilar a religião à filosofia. Nessa polêmica, esses intelectuais tomaram partido a favor de Strauss, e reivindicaram, com ele, o direito da filosofia e da ciência de submeter a religião a uma análise crítica.

O próximo passo foi a tentativa de modificação da filosofia de Hegel noutro ponto essencial: sua adaptação ao liberalismo. Isso implicava superar a contradição implícita entre o núcleo dialético, que apresenta um progresso contínuo, e o sistema político conservador. Para isso, era preciso separar o método dialético do sistema, libertando o movimento dialético da Ideia para o futuro, já que Hegel o tinha detido no presente. Então para transformar a dialética num instrumento de combate à reação, esta não deveria apenas deduzir o presente do passado, mas também deveria prever o futuro, com base no presente, para determinar a marcha racional da história.

\begin{tabular}{|c|c|c|c|c|}
\hline Q Rovista Dialectus & Ano 5 & n. 12 & Janeiro - Julho 2018 & p. $265-283$ \\
\hline
\end{tabular}




\section{BREVES INDICACÕES SOBRE O CONTEXTO HISTÓRICO, OS... Frederico Jorge Ferreira Costa}

No entanto, havia uma determinação histórica própria da realidade alemã. Como a esquerda hegeliana não encontrava na burguesia alemã, devido sua debilidade e suas tendências semiconservadoras, o apoio revolucionário encontrado pelos enciclopedistas franceses do século XVIII junto à sua burguesia, o movimento da esquerda hegeliana confinou-se em uma tendência essencialmente ideológica. Os jovens hegelianos devedores do idealismo hegeliano e sem duvidar da capacidade do "Espírito" para transformar o mundo, além de incapazes de levar o combate ao plano político e social, se mantiveram em sua luta no plano das ideias. Pensavam que, como o desenvolvimento das ideias determinava o da realidade, bastava eliminar em teoria os elementos irracionais incluídos no real para imprimir no desenvolvimento da história humana um sentido racional.

Mesmo com essas limitações, o interessante é que, ao opor o movimento dialético das ideias ao sistema conservador de Hegel, a esquerda hegeliana destacava da filosofia deste uma doutrina da ação adaptada às aspirações liberais da burguesia. A expressão dessa perspectiva foi dada nos Prolegômenos à filosofia da história de 1838, de August von Cieszkowski (1814-1894). A tese central era substituir a filosofia de Hegel, puramente especulativa, por uma filosofia da ação, e sustentava, contra Hegel, que a filosofia não devia limitar-se a extrair do passado as leis da história, senão que devia apoiar-se nestas para transformar o mundo.

Cieszkowski preconizava uma filosofia da ação, da atividade prática, da "práxis" - conceito que depois seria retomado por Karl Marx -, que permitiria aos seres humanos dirigirem seus destinos e colaborarem com a história do mundo. Em decorrência disso, o pensador da esquerda hegeliana indicava como expressão de uma filosofia da ação as novas doutrinas socialistas, como em especial as ideias de Fourier, que eram criticadas por seu apego ao presente, deixando de lado, a determinação essencialmente racional do futuro. Nessa perspectiva, o pensamento era entendido como vontade atuante em oposição à realidade presente. De certa maneira, a obra referida apresentava elementos progressivos: 1) superava o liberalismo e o pensamento burguês ao indicar como fim da história a reorganização socialista da sociedade; 2) levantava, sob influência de Saint-Simon (1760-1825), a importância das relações de produção; 3) concebia, antes de Karl Marx, ainda de forma idealista, a filosofia como "práxis", isto é, como uma filosofia integrada à atividade social (CORNU, 1955; KOLAKOWSKI, 1980).

\begin{tabular}{|c|c|c|c|c|}
\hline Revista Dialectus & Ano 5 & n. 12 & Janeiro - Julho 2018 & p. $265-283$ \\
\hline
\end{tabular}




\section{BREVES INDICACÕES SOBRE O CONTEXTO HISTÓRICO, OS...}

Frederico Jorge Ferreira Costa

Para defender suas ideias, intelectuais da esquerda hegeliana encontraram nos Anais de Halle para a ciência e a arte alemãs, fundado em 1838 por Arnold Ruge (1802-1880) e Theodor Echtermeyer (1805-1844), espaço para combater o órgão conservador dos velhos hegelianos, os Anais berlinenses de crítica científica. No início, os Anais de Halle não possuíam caráter político e se ocupavam quase exclusivamente de arte e de literatura. Mas, como defendiam os direitos da crítica, a independência da ciência e do Estado frente à Igreja e defendiam David Strauß contra os ataques sofridos, foram imediatamente atacados pelos reacionários e conduzidos à oposição política.

O governo prussiano, alarmado pela crítica que David Strauss fez aos dogmas, e inquieto pelas consequências levadas pela filosofia hegeliana, acentuou sua política reacionária e condenou, não só o movimento dos jovens hegelianos, senão que chegou a rechaçar o hegelianismo, até então considerado como firme sustentáculo do Estado, e que agora lhe parecia perigoso. O ministro de Instrução Pública e de Culto, Alterstein, que até então havia protegido os hegelianos, não se atreveu a apoiá-los abertamente, se negou a nomear A. Ruge professor titular de Halle, o qual contribuiu sem dúvida para que este se lançasse mais abertamente à oposição (tradução livre, CORNU, 1955, p. 148).

Começa, então, o movimento progressivo de profanação da religiosidade, que encontrará sua grande expressão, em 1841, com Ludwig Feuerbach (1804-1872) em

A essência do cristianismo (2007). Em síntese, a crítica feuerbachiana à religião e sua extensão à filosofia de Hegel

[...] representam a substituição do Absoluto (Deus ou Ideia) pelo homem real, que para Feuerbach já não é propriamente um predicado do espírito, mas sim um ente real, verdadeiro sujeito, que, sem deixar de ser natureza, é também espírito. E exatamente por sê-lo, por estar dotado de razão, vontade e sentimento, ao notar sua precariedade, cria um Deus no qual projeta sua aspiração à eternidade e à perfeição (VÁZQUEZ, 2011, p. 91).

Em relação à religião, Feuerbach (2007), indo além de Strauß, identificou que Deus não é um ente objetivo, pois não existe em si e por si, ou seja, como sujeito autônomo, mas, sim, como objeto, como um predicado humano. Então, o homem se objetiva nesse objeto que é ele mesmo: sua essência objetivada. No entanto, o homem em geral não tem consciência de que o objeto da religião - Deus - é um produto seu, não se reconhecendo nele. Então, na relação religiosa sujeito e objeto conformam-se como uma alienação. De fato, Deus não passa da essência humana hipostasiada, a consciência humana de si apresentada de forma invertida. Isso traz consequências nefastas para o homem, pois quanto mais o predicado (Deus) se enriquece, mais o

\begin{tabular}{|c|c|c|}
\hline Q Rovista Dialectus & Ano 5 & n. 12 \\
\hline
\end{tabular}




\section{BREVES INDICACÕES SOBRE O CONTEXTO HISTÓRICO, OS...}

Frederico Jorge Ferreira Costa

sujeito homem se empobrece. Eis aqui, a partir da crítica à estrutura da religião cristã, a indicação das determinações de toda alienação - que inclusive ajudarão Marx a compreender o trabalho alienado e a relação entre Estado e sociedade civil: 1) o sujeito é ativo e com sua atividade cria o objeto; 2) o objeto é produto da atividade do sujeito, mas este não se reconhece no objeto; 3) o objeto é apreendido como algo alheio ao sujeito; 4) o objeto apresenta um poder, que em sua imanência não possui, e que se volta contra o sujeito dominando-o, convertendo-o em predicado de sua criação.

Dando continuidade à crítica da religião, Feuerbach subverte inteiramente os termos da problemática hegeliana - uma vez que, a filosofia hegeliana sanciona o "espírito absoluto" -, em Feuerbach, tem-se a determinação do caráter alienado desse "espírito absoluto", isto é, ele é um produto dos homens. Estendendo a crítica ao conjunto da filosofia hegeliana, não mais como os neohegelianos anteriores - revelando uma tensão interior entre sistema e método -, mas criticando o idealismo como fundamento do pensamento de Hegel. A filosofia hegeliana seria a última forma de idealismo especulativo, que intenta realizar a unidade do espírito e da matéria, do homem e da natureza, por meio da espiritualização da totalidade do real. Nesses termos, a realidade concreta, a natureza, só aparece como exteriorização, alienação do Espírito, posto como princípio primeiro dos seres e das coisas.

No contexto histórico da realidade alemã do século XIX, o movimento de crítica à religião perpetrado pela esquerda hegeliana transitava inevitavelmente para uma crítica da política, pois o primeiro passo para criticar o Estado na confederação germânica era a crítica à religião. $\mathrm{O}$ ateísmo, o naturalismo e a luta contra o obscurantismo da ala direita hegeliana abriram os caminhos para crítica da política. $\mathrm{O}$ que não deixou de ser percebido pela reação que não nutria nenhuma simpatia por essa postura teórica. Demonstração disso foi dada pelo monarca prussiano Frederico Guilherme IV (1795-1861) que ascendeu ao trono em 1840, e deu um golpe na esquerda hegeliana nomeando para reitor da Universidade de Berlim Schelling ${ }^{12}$, expressão ideológica da negação do pensamento dialético e histórico. Mas, não parou nessa atitude.

12 Inicialmente amigo e colaborador de Hegel na juventude até 1805/1806, quando rompem, passando Schelling a involuir, segundo Hegel, no sentido de pensar uma filosofia da revelação e da intuição, o que no limite, irá determinar uma apreciação irracionalista do mundo, estreitamente compatível com o obscurantismo do sacro império alemão.

\begin{tabular}{|l|l|l|l|l|}
\hline Qovista Dialectus & Ano 5 & n. 12 & Janeiro - Julho 2018 & p. 265-283 \\
\hline
\end{tabular}




\title{
BREVES INDICACÕES SOBRE O CONTEXTO HISTÓRICO, OS...
}

Frederico Jorge Ferreira Costa

A face real do tacão prussiano mostra-se primeiro em 1841 e já se dirige contra os jovens hegelianos: Bauer tem seus cursos proibidos em Berlim. E, nos dois anos seguintes, a fratura entre os jovens hegelianos e o Estado prussiano torna-se irrecorrível: em março de 1842 Bauer é excluído da universidade e as medidas repressivas e policiais multiplicam-se, alcançando o ápice com a expulsão de Herweg e com a interdição, efetuada com a direta intervenção de Frederico Guilherme IV, de todas as publicações liberais (e a sua apreensão quando editadas no exterior) (NETTO, 2004, p. 19).

Conforme Heinrich (2018), Bruno Bauer (1809-1882) destacou-se na controvérsia em torno da obra de Strauß, A vida de Jesus, publicou nos Anais berlinenses de crítica científica uma resenha crítica na qual ele defendia a historicidade dos Evangelhos, o que o colocava na direita hegeliana. No entanto, a situação política e sua evolução intelectual o colocaram posteriormente à esquerda de Strauß ao afirmar que os Evangelhos não seriam apenas um mito surgido na comunidade, mas produtos literários daqueles que os haviam escrito. Em 1842, sua permissão para lecionar teologia foi revogada.

Em sua radicalização, Bruno Bauer apresenta o desenvolvimento infinito da Consciência Universal, negando a toda substância, a toda forma religiosa ou política determinada o direito de encarná-la de maneira absoluta. Essa tese destruía de vez o sistema conservador de Hegel, mantendo apenas o desenvolvimento dialético infinito. Tal rompimento com Hegel se deu às custas de reduzir todo o movimento da história a um desenvolvimento puramente espiritual, separando o espírito da realidade concreta com a oposição entre Espírito e Substância, o que reduzia a atividade prática a uma crítica dos dogmas e das instituições do Estado. Mesmo assim,

\begin{abstract}
Ao orientar de forma mais decidida que Cieszkowisk a filosofia em direção à transformação radical do estado de coisas do existente, Bruno Bauer abria, com Ruge, o caminho que levava do liberalismo religioso ao liberalismo político. Com efeito, ao proclamar o direito da crítica a rechaçar toda realidade positiva que, só pelo fato de sua existência, tende a tornar-se irracional, Bauer justificava, no plano teórico, a crítica revolucionária mais audaz e proporcionava a arma que havia de servir à esquerda hegeliana para minar os fundamentos, não já da religião cristã, senão também do Estado prussiano (tradução livre, CORNU, 1955. p. 161).
\end{abstract}

A discussão política posta na ordem do dia passa a girar em torno do Estado prussiano, mais exatamente a partir da expectativa que a sociedade mantinha em relação a ele.

Em síntese, a esquerda hegeliana tentou construir uma filosofia que fosse prática na perspectiva de influir na transformação da realidade alemã do século XIX. Criticou dois pilares da estrutura social alemã: a religião e o Estado. Daí as concepções

\begin{tabular}{|l|l|l|l|l|}
\hline Q Povista Dialectus & Ano 5 & n. 12 & Janeiro - Julho 2018 & p. 265-283 \\
\hline
\end{tabular}




\section{BREVES INDICACÕES SOBRE O CONTEXTO HISTÓRICO, OS... Frederico Jorge Ferreira Costa}

de David Strauß e Bruno Bauer sobre a religião e as teses de Arnold Ruge no cenário posterior à morte de Hegel. Essa tendência intelectual expressava as necessidades de ruptura com o atraso alemão, sob a forma de críticas às estruturas irracionais mais evidentes do mundo alemão congeladas na religião cristã e no Estado prussiano. Tais estruturas, segundo as coordenadas da esquerda hegeliana, barravam o desenvolvimento infinito do Espírito, da Ideia ou da Consciência Universal. Noutras palavras, a esquerda hegeliana buscava transformar por meios das ideias, isto é, da atividade teórica, o mundo.

No entanto, a própria realidade política - o Estado prussiano - com seus atos reais, efetivos, explicitava a inoperância e a inatividade dessa prática teórica.

Justamente essa limitação e essa impotência da atividade teórica era tanto mais evidente quanto mais se confiava em sua onipotência. Na verdade, os intelectuais mais destacados da esquerda hegeliana apresentavam como um problema a resolver a necessidade de passar de uma teoria para a transformação da realidade. No entanto, a teoria em si, nunca deixou de ser teoria e jamais foi uma práxis efetiva e transformadora.

Nessas coordenadas contraditórias, nos marcos de uma Alemanha atrasada e de uma burguesia débil, a ação progressiva da intelectualidade democrático-liberal pequeno-burguesa, representada pela esquerda hegeliana, chegou aos seus limites históricos. Em primeiro lugar, pela estrutura social e pela dinâmica da luta de classes.

Nas primeiras décadas do século XIX, como já visto, a prosperidade industrial converteu a Prússia, de um país fundamentalmente agrário, em um Estado industrial. Na Renânia, em particular, ocorreu um rápido desenvolvimento das cidades, onde se formou uma burguesia rica e uma classe operária concentrada e cada vez mais numerosa. Como resposta a essa nova situação, a burguesia, que passou a dirigir forças produtivas crescentes, tomou consciência de seu papel social e buscou mais espaço político para seus interesses.

No entanto, a conformação de uma ideologia liberal, apoiada por uma burguesia que se fortalecia, foi simultânea ao nascimento do socialismo e do comunismo. Também, com as primeiras revoltas do proletariado alemão. Por isso, a característica do movimento político de oposição, na Alemanha depois de 1830, foi a coexistência do movimento liberal e do movimento socialista/comunista, que tenderam a dissociar-se cada vez mais um do outro.

\begin{tabular}{|l|l|l|l|l|}
\hline Qevista Dialectus & Ano 5 & n. 12 & Janeiro - Julho 2018 & p. 265-283 \\
\hline
\end{tabular}




\section{BREVES INDICACÕES SOBRE O CONTEXTO HISTÓRICO, OS...}

Frederico Jorge Ferreira Costa

Em razão da existência e da ascensão do proletariado, o liberalismo não adquiriu na Alemanha o caráter revolucionário que tinha tido na França do século XVIII. Diferentemente da burguesia francesa do século XVIII, que em função da débil concentração da produção, isto é, que passava do estágio artesanal para o manufatureiro, não conheceu um proletariado organizado e forte, capaz de dirigir toda sua ação contra as potências conservadoras - monarquia, nobreza, Igreja. A burguesia alemã, porém, formada na época em que a produção da Alemanha passava quase sem interrupção da fase artesanal à fabril, teve que lutar desde o começo não apenas contra os poderes reacionários, mas também, contra um proletariado cada vez mais numeroso. A burguesia alemã, para sua própria sobrevivência, recuou de qualquer radicalismo, contentando-se com uma postura semiconservadora, que tendia a lograr um acordo com as forças reacionárias, contra seu inimigo comum, as massas operárias.

Assim, o acirramento da luta de classes entre burguesia e proletariado, que tomavam posição contra a reação, induziu o desenvolvimento paralelo de um movimento liberal e de um movimento democrático e socialista. Esse duplo caráter da oposição causou a crise da esquerda hegeliana e sua superação pelo marxismo, expressão dos interesses históricos de um novo protagonista social: o proletariado.

\section{REFERÊNCIAS}

CORNU, Auguste. Karl Marx et Friedrich Engels: leur vie est leur ouvre - Tome Premier - Les années d'enfance et de jeunesse, la gauche hégélienne, 1818/1820-1844. Paris: Presses Universitaires de France, 1955.

COUTINHO, Carlos Nelson. O estruturalismo e a miséria da razão. 2 ed. São Paulo: Expressão Popular, 2010.

STRAUSS, David. The life of Jesus: critically examined. Fourth Edition. London: Swan Sonnenschein \& CO. Lim., 1902.

ENGELS, Friedrich. Ludwig e o fim da filosofia clássica alemã. In: MARX, Karl \& ENGELS, Friedrich. Obras escolhidas. Tomo III. Lisboa-Moscovo: "Avante!" Progresso, 1985.

\begin{tabular}{|c|c|c|}
\hline Q Rovista Dialectus & Ano 5 & n. 12 \\
\hline
\end{tabular}




\section{BREVES INDICACÕES SOBRE O CONTEXTO HISTÓRICO, OS...}

Frederico Jorge Ferreira Costa

FEUERBACH, Ludwig. A essência do cristianismo. Petrópolis, RJ: Vozes, 2007.

HEINRICH, Michael, Karl Marx e o nascimento da sociedade moderna: biografia e desenvolvimento de sua obra, volume 1: 1818-1841. São Paulo: Boitempo, 2018.

KOLAKOWSKI, Leszek. Las principales corrientes del marxismo: I - Los fundadores. Madrid: Alianza Editorial, 1980.

LÖWITH, Karl. De Hegel a Niestzshe: a ruptura revolucionária no pensamento do século XIX, Marx e Kierkegaard. São Paulo: Editora da UNESP, 2014.

MÉSZÁROS, István. Para além do capital. São Paulo/Campinas: Boitempo/Unicamp, 2002.

NETTO, José Paulo. Marxismo impenitente; contribuição à história da idéias marxistas. São Paulo: Cortez, 2004.

TAYLOR, Charles. Hegel: sistema, método e estrutura. São Paulo: É Realizações Editora, 2014.

VÁZQUEZ, Adolfo Sánchez. Filosofia da práxis. $2^{\mathrm{a}}$ ed. Buenos Aires/São Paulo: Clacso/Expressão Popular, 2011.

\begin{tabular}{|l|l|l|l|l|}
\hline Q Rovista Qialectus & Ano 5 & n. 12 & Janeiro - Julho 2018 & p. 265-283 \\
\hline
\end{tabular}

